\title{
Creating a Safe Operating Space for Iconic Ecosystems
}

\author{
By M. Scheffer ${ }^{1}$, S. Barrett ${ }^{2}$, S. R. Carpenter ${ }^{3}$, C. Folke, A. J. Green ${ }^{5}$, M. Holmgren $^{6}$, T. P. Hughes ${ }^{7}$, S. \\ Kosten $^{8}$, I. A. van de Leemput ${ }^{1}$, D.C. Nepstad ${ }^{9}$, E. H. van Nes ${ }^{1}$, E. T.H.M. Peeters ${ }^{1}$ and B. Walker ${ }^{10}$
}

Although some ecosystem responses to climate change are gradual, many ecosystems react in highly non-linear ways. They show little response until a threshold or tipping point is reached where even a small perturbation may trigger collapse into a state from which recovery is difficult (1). Increasing evidence shows that the critical climate level for such collapse may be altered by conditions that can be managed locally. These synergies between local stressors and climate change provide potential opportunities for pro-active management. Although their clarity and scale make such local approaches more conducive to action than global greenhouse gas management, crises in iconic UNESCO World Heritage sites illustrate that such stewardship is at risk of failing.

The term "safe operating space" frames the problem of managing our planet in terms of staying within acceptable levels or "boundaries" for global stressors (2). Uncertainty is accounted for by keeping on the safe side of such boundaries. The safe levels of different stressors at global scales are mostly considered independently. However, in ecosystems a safe level for one stressor is often strongly dependent of the level of other stressors. This implies that if such synergies are understood, local stressors may be effectively managed to enhance tolerance to global climate change (Fig 1).

LOCAL AND FEASIBLE. The feasibility of managing the climate sensitivity of ecosystems

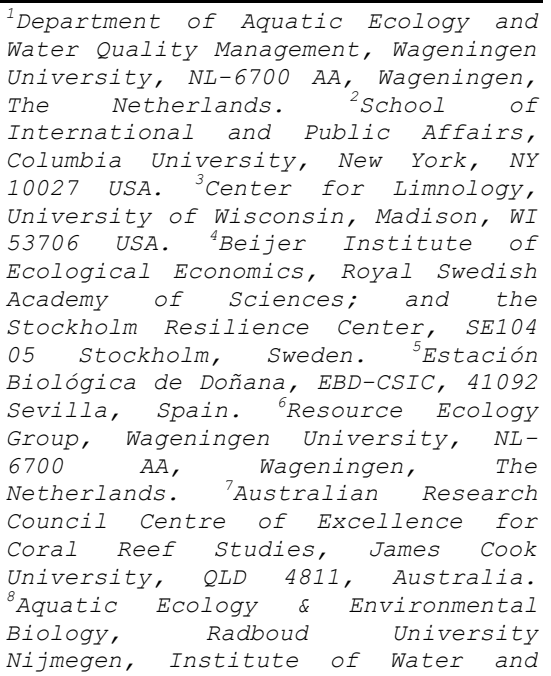

is becoming increasingly evident. Obviously, local interventions are no panacea for the threats of climatic change. For example, melting of arctic sea ice with its far-reaching ecological consequences cannot be arrested by local management. However, ways of building climate resilience are emerging for a variety of ecosystems, ranging from control of local sources of ocean acidification (3), to management of grazing pressure on dry ecosystems (4). We focus here on lakes, coral reefs and tropical forests.

In lakes, warming and nutrient loading have similar effects on the likelihood that the ecosystem will tip into encroachment by floating plants or into dominance by toxic cyanobacteria (5). Experiments and field studies on different scales revealed intricate mechanisms that drive the synergy between effects of warming and nutrient load, e.g., boosted nutrient cycling, and shifts in the competitive advantage that favor small, rapidly reproducing fish species, cyanobacteria and floating plants $(5,6)$. While the synergy of climate and nutrient stressors implies double jeopardy to many wetlands, the good news is that reducing the nutrient load can compensate for effects of warming. For example, data from lakes across continents and climate zones suggest that a reduction in nutrient concentrations by one third can compensate for the effect of $1^{\circ} \mathrm{C}$ increase in water temperature when it comes to the risk of cyanobacterial dominance (6).

In coral reefs, resilience depends strongly on locally manageable stressors such as fishing pressure and water quality. For example, the take-over of most Caribbean reefs by seaweeds was triggered by sea-urchin mortality, but facilitated in many locations by high nutrient loading and overharvesting of fish functional groups that controlled the sea weeds (7). On the Great Barrier Reef, coral recovery rates after the 1998 bleaching event were markedly suppressed by experimental exclusion of herbivorous fishes (8). Local conservation efforts can help in maintaining and enhancing resilience, and in limiting longer-term damage from bleaching and other climate-related impacts.

In tropical forests, resilience is under pressure from climate change as well as local stressors such as deforestation, logging and fire (9). Forests become stressed by increases in temperature (10) and by greater rainfall variability (4). One important near-term risk from drought is a self-reinforcing shift to a contrasting fire-maintained state. Recent experiments confirm cascading effects of a decline in canopy cover, which favor invasion by flammable grasses (11). The removal of trees makes the forest more fire-prone, increasing the risk of further transition to open woodland in dry years $(11,9)$. In addition, there is a substantial positive feedback effect of forest cover on regional precipitation, implying that loss of forest contributes to overall reduction in rainfall (9). Thus, maintaining a critical mass of forested areas and preventing opening of the closed canopy structure are powerful tools to enhance the safe operating space of tropical forest in the face of rising drought risks.

WORLD HERITAGE AT RISK. In spite of the solid scientific basis for managing climate resilience in such ecosystems, failure to do so is putting globally important ecosystems at risk. We highlight crises faced by three iconic World Heritage Areas.

The Doñana wetlands in southern Spain provide the most important wintering site for waterfowl in Europe. They contain the largest temporary pond complex in Europe, with a diversity of amphibians and invertebrates. Despite the site's protected status, the marshes are threatened by eutrophication due to pollution and reduced flow of incoming streams, promoting toxic cyanobacterial blooms and dominance by invasive floating plants that create anoxic conditions in the water. In addition, groundwater extraction for strawberry culture and beach tourism also has major impacts (12). Little has been done to control these local stressors, leaving Doñana unnecessarily vulnerable to climate change. UNESCO has just rated this World Heritage Site as under 'very high threat'.

The Great Barrier Reef is the largest coral system in the world. In response to multiple threats, fishing has been prohibited since 2004 over 33\% of the Great Barrier Reef Marine Park, and efforts have begun to reduce runoff of nutrients, pesticides, herbicides and sediments from land. However, these interventions may be too little, too late. Approximately half of the coral cover has been lost in recent decades (13), and the outlook is 
"poor, and declining" with climate change, coastal development and dredging as major future threats (14). The World Heritage Committee has warned that in the absence of a solid long-term plan, it would consider listing the reef as "in danger" in 2015 (15).

The Amazon rainforest is one of the world's great biological treasures and a vital component of Earth's climate system. Yet this ecosystem is under increasing pressure from climate change as well as local stressors such as logging and forest fire (9). Brazil has shown leadership by slowing down Amazon deforestation by $70 \%$ (16), and by creating the largest protected area (PA) network in the world. Yet these successes are now being partially undermined by major infrastructure and natural resource extraction projects, and by shifts in legislation (17).

FRAMING FOR ACTION. The evidence we have for enhancing climate resilience of ecosystems places direct responsibility on governments to ensure implementation. However, investment will only happen if costs of refraining from activities that undermine resilience are distributed in ways that lead to effective action. Realizing such incentive schedules may be challenging. However, there are three specific reasons why building a safe operating space for ecosystems by controlling local stressors is more conducive to immediate action than global control of greenhouse gases.

From global to local commons: Potential incentives for local protection are much stronger than those to supply the global public good of abating greenhouse gas emissions (18), for the same reason that countries tend to favor adaptation over mitigation. Mitigation requires global collective action and is vulnerable to free riding, whereas adaptation can be done unilaterally, with benefits accruing almost exclusively to the country doing the adaptation. However, iconic ecosystems also provide a global public good. This is why they are on the World Heritage list in the first place. In some cases the local interventions can result in substantial global mitigation. For instance, slowing down Amazon deforestation made Brazil a global leader in climate change mitigation (16).

From high to low uncertainty: Perceived uncertainty has often paralyzed policy (19), and experimental evidence suggests that uncertainty about climate change tipping points undermines efforts to avoid crossing a dangerous threshold (20). There is less uncertainty on the ecosystem level than on the global level when it comes to effects of management options. From negative to positive framing: Gloom and doom perceptions may backfire to block action. Terms such as 'extreme events' and 'catastrophic transitions' may express the urgency of the matter. However, social experiments reveal that accounts of disastrous future effects of climate change can invoke cognitive dissonance that causes many people to disbelieve climate change altogether. This response disappears if a feasible approach to take action and abate the problems is presented simultaneously (21). A positive, action-oriented framing of a safe operating space for the world's iconic ecosystems may help stimulate societal consensus that climate change is real and should be addressed.

\section{REFERENCES}

1. M. Scheffer, et al, Nature 413, 591 (2001)

2. J. Rockström et al., Ecology and Society 14, (2009)

3. R. P. Kelly et al., Science 332, 1036 (2011)

4. M. Holmgren, M. Hirota, E. H. Van Nes, M. Scheffer, Nature Climate Change 3, 755 (2013)

5. B. Moss et al., Inland Waters 1, 101 (2011)

6. S. Kosten et al., Global Change Biology 18 , 118 (2012)

7. T. P. Hughes et al., Science 301, 929 (2003)

8. T. P. Hughes, et al., Current Biology 17, 360 (2007)

9. Y. Malhi, et al, Science 319, 169 (2008)

10. K. J. Feeley, et al, Ecol. Lett. 10, 461 (2007)

11. P. M. Brando et al., Proceedings of the National Academy of Sciences, 111(17): 6347 (2014)

.12. C. Guardiola-Albert, C. R. Jackson, Wetlands 31, 907 (2011)

13. D. R. Bellwood, T. P. Hughes, C. Folke, M. Nystrom, Nature 429, 827 (2004)

14. A Great Barrier Reef Marine Park, Great Barrier Reef Outlook Report 2014: In brief. (Great Barrier Reef Marine Park Authority, Townsville, 2014), pp. 25.

15. D. Normile, L. Dayton, Science 346, 683 (2014)

16. D. Nepstad et al., Science 344, 1118 (2014)

17.J. Ferreira et al., Science 346, 706 (2014)

18. E. Ostrom, et al, Science 284, 278 (1999)

19. N. Oreskes, E. M. Conway, Merchants of Doubt: How a Handful of Scientists Obscured the Truth on Issues from Tobacco Smoke to Global Warming. (Bloomsbury Press, New York, 2010), pp. 368.

20. S. Barrett, A. Dannenberg, Nature Climate Change 4, 36 (2014)

21. M. Feinberg, R. Willer, Psychological Science 22, 34 (2011)

Acknowledgements: M.S. is supported by an ERC-advanced grant and Spinoza award. C.F. is supported by the Stellenbosch Institute for Advanced Study. SRC's research is supported by NSF. A.J.G. was supported by a WIMEK research fellowship and S.K. by a NWO-Veni grant 86312012 . M.S., C.F. and S.R.C. are also at the South American Institute for Resilience and Sustainability Studies. This work was carried out under the program of the Netherlands Earth System Science Centre (NESSC).

10.1126/science. 


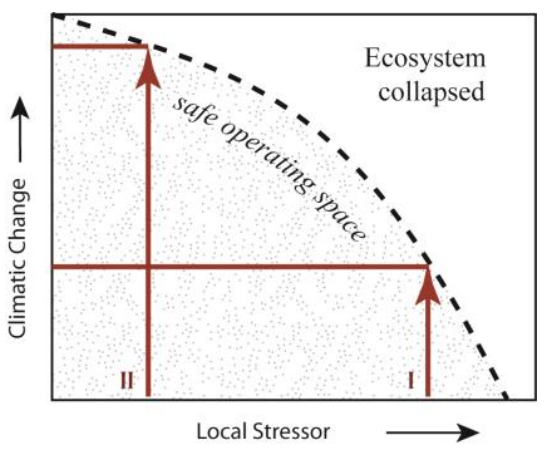

Fig. 1 Schematic representation of safe operating space. In ecosystems at risk of collapse, safe boundaries for local stressors such as harvest rates or pollution often change with climate change. A local stressor that is currently at a safe level (I), needs to be adjusted to a lower value to keep the system within the safe operating space in a future climate (II).
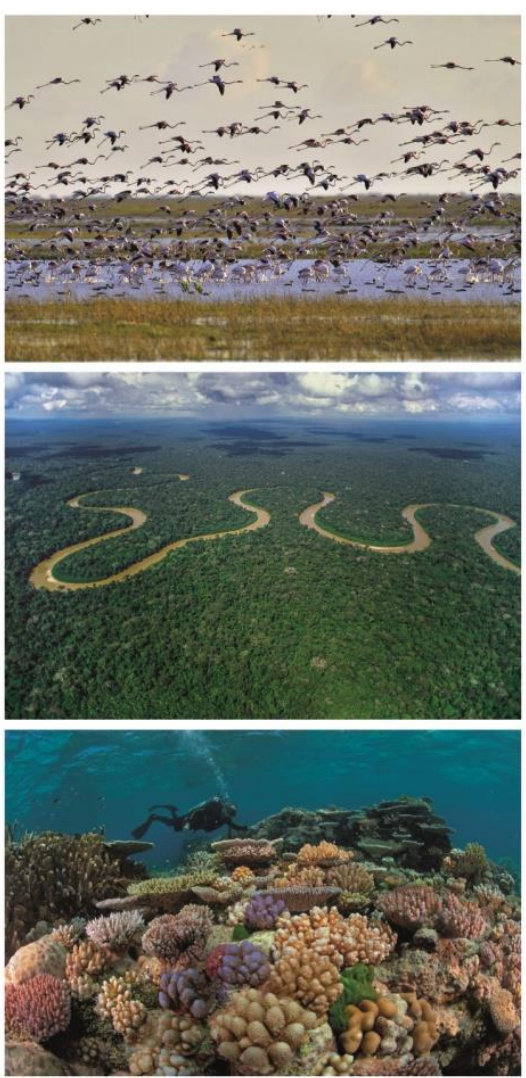

Fig. 2. Examples of iconic ecosystems where climate change may trigger transitions to a different state. From top to bottom: the Doñana wetlands, the Amazon rainforest and the Great Barrier Reef (credits from top to bottom: Jorge Sierra; André Baertschi / wildtropix.com; David Doubilet, National Geographic Creative). 